\title{
Link-Placement Characterization of Optical Phase Conjugation for Nonlinearity Compensation
}

Da Ros, Francesco; Yankov, Metodi Plamenov; Porto da Silva, Edson; Lillieholm, Mads; Forchhammer, Søren; Galili, Michael; Oxenløwe, Leif Katsuo

Published in:

Optical Fiber Communication Conference 2018

Link to article, DOI:

10.1364/OFC.2018.W3E.3

Publication date:

2018

Document Version

Peer reviewed version

Link back to DTU Orbit

Citation (APA):

Da Ros, F., Yankov, M. P., Porto da Silva, E., Lillieholm, M., Forchhammer, S., Galili, M., \& Oxenløwe, L. K. (2018). Link-Placement Characterization of Optical Phase Conjugation for Nonlinearity Compensation. In Optical Fiber Communication Conference 2018 Optical Society of America. https://doi.org/10.1364/OFC.2018.W3E.3

\section{General rights}

Copyright and moral rights for the publications made accessible in the public portal are retained by the authors and/or other copyright owners and it is a condition of accessing publications that users recognise and abide by the legal requirements associated with these rights.

- Users may download and print one copy of any publication from the public portal for the purpose of private study or research.

- You may not further distribute the material or use it for any profit-making activity or commercial gain

- You may freely distribute the URL identifying the publication in the public portal 


\title{
Link-Placement Characterization of Optical Phase Conjugation for Nonlinearity Compensation
}

\author{
F. Da Ros, M.P. Yankov, E.P. da Silva, M. Lillieholm, S. Forchhammer, M. Galili, L.K. Oxenløwe \\ DTU Fotonik, Technical University of Denmark, DK-2800 Kongens Lyngby, Denmark, fdro@fotonik.dtu.dk
}

\begin{abstract}
The impact of the OPC offset on the nonlinearity compensation is experimentally investigated, achieving gains up to $0.6-\mathrm{dB}$ SNR and 0.17-bit/symbol mutual information with optimal mid-link OPC for dispersion-compensated transmission up to $966 \mathrm{~km}$. (C) 2018 The Author(s) OCIS codes: (060.4510) Optical communications; (190.4380) Nonlinear optics, four-wave mixing,
\end{abstract}

\section{Introduction}

The impact of Kerr nonlinearity currently limits the performance of coherent transmission systems. A strong research effort has therefore been directed towards techniques for mitigation or at compensation of the nonlinear distortion experienced by signals during transmission. While techniques based on digital signal processing (DSP) are particularly effective in compensating for intra-channel nonlinearity, analog bandwidth limitations make them impractical for addressing inter-channel nonlinear distortion [1]. All-optical techniques, instead, may be more suited for tackling cross-channel nonlinearity due to their larger operation bandwidth. Amongst them, in-line optical phase conjugation (OPC) has been proven effective for nonlinearity compensation. Several impressive demonstrations show significant improvement achieving bandwidths up to $2.3 \mathrm{THz}$ [2].

The improvement provided by in-line OPC for compensation of Kerr nonlinearity is however strongly dependent on the transmission link fulfilling rather stringent dispersion and power symmetry requirements [3]. These requirements limit the practical link configurations where compensation is achieved. Dispersion-managed transmission with lumped erbium-doped fiber amplifiers (EDFAs) or links with distributed Raman amplification can provide sufficient symmetry to enable performance improvement by mid-link OPC [3-5].

In a practical scenario, implementing the OPC operation at the exact mid-point in a link may not be possible or desirable. Hence, the impact of OPC position on the nonlinearity compensation has been numerically investigated for dispersion-unmanaged links in [1, 6, 7]. Additionally, in [1,7], the potential to compensate for an offset in OPC position by lower complexity DBP has been proposed and numerically evaluated.

In this work, we provide an experimental analysis of the impact of the OPC position on the achievable improvement in mutual information (MI) and the effective receiver signal-to-noise ratio (SNR) for dispersioncompensated transmission up to $966 \mathrm{~km}$. The position of the OPC is varied in steps of $161 \mathrm{~km}$ and the performance for 16-GBd 64- quadrature amplitude modulation (QAM) is benchmarked against straight (without OPC) transmission in a 5-channel wavelength division multiplexing (WDM) scenario.

\section{Experimental setup}

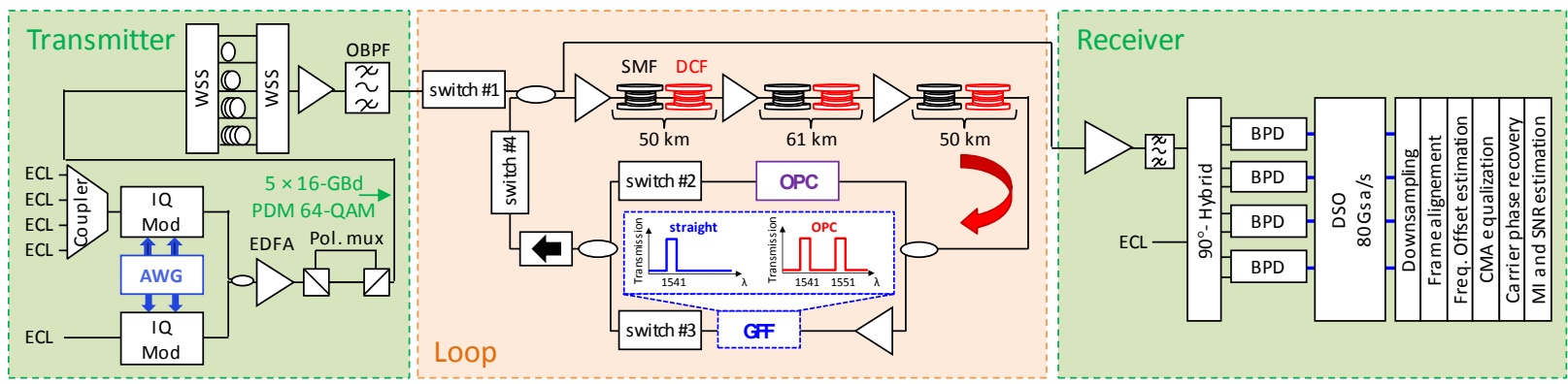

Fig. 1. (a) Experimental setup for the dispersion-compensated transmission with OPC: inset shows the transmission profiles for the GFF opening only the signal band and both signal and idler band for straight and OPC-based transmissions, respectively.

The experimental setup is shown in Fig. 1. Five external cavity lasers (ECLs) are modulated in two IQ modulators (one for the central channel under test, one for the four interferers) driven by an arbitrary waveform generator (AWG, $64 \mathrm{GSa} / \mathrm{s}$ ) operating at $16 \mathrm{GBd}$. The waveform loaded in the AWG consists of random data mapped into a 64-QAM constellation and interleaved with quadrature phase shift keying (QPSK) pilot symbols, used for equalization and phase noise tracking, at a pilot rate of $10 \%$. A root-raised cosine pulse shaping (roll-off of 0.01 ) is applied. After modulation, a polarization division multiplexed (PDM) signal is generated with a delay-and-add polarization multiplexing emulator. The five channels are individually decorrelated using wavelength selective 
switches (WSSs) and fiber delays (delay $>50$ symbols), and then injected into the transmission link. The link is based on a recirculating loop setup consisting of three dispersion-compensated spans (loop length of $161 \mathrm{~km}$ ), combining single mode fiber (SMF) and dispersion compensating fiber (DCF). Span losses are compensated by EDFAs which are used to vary the launch power at the input of each span. For every loop turn, two acousto-optic switches control if the signal is conjugated in the OPC setup (switch \#2 closed) or simply amplified in an EDFA followed by a programmable gain-flattening filter (GFF) which suppresses out-of-band amplified spontaneous emission (ASE) noise (switch \#3 closed). As shown in the inset of Fig. 1, for straight transmission the GFF selects and flattens a 4-nm bandwidth around the signal wavelength $(1540.75 \mathrm{~nm})$. For the OPC-based transmission, the GFF selects two 4-nm bands, one for the signal and one for the idler. This requires a more careful balance of the attenuation of the two bands and results in a noise band always co-propagating with the signal/idler band (the impact of this effect on the overall transmission performance is discussed below). After transmission, the central channel is received with a pre-amplified coherent receiver based on a digital sampling oscilloscope (DSO, 80 GSa/s) and off-line DSP consisting of (in order) frequency offset estimation, pilot-aided equalization [8], phase recovery and MI and SNR estimation [9]. The MI is estimated by using an auxiliary probability distribution derived by the phase recovery algorithm [9]. The estimations are carried out over $10^{6}$ symbols leading to a measurement precision better than 0.05 bit/symbol and $0.1 \mathrm{~dB}$ for MI and SNR, respectively.
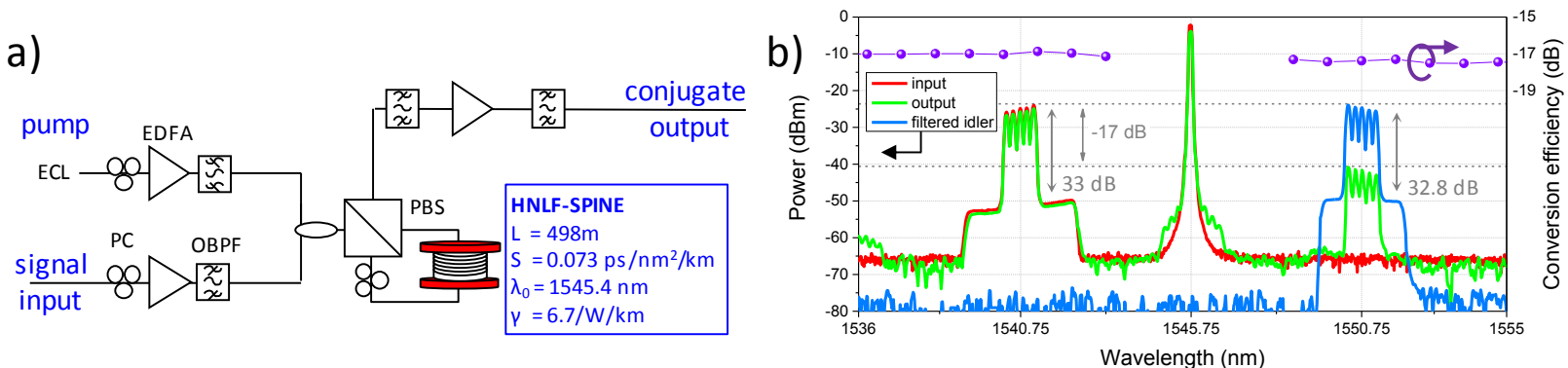

Fig. 2. (a) Setup of polarization-diversity based OPC module and (b) OPC input and output spectra, and CE of the HNLF-SPINE.

The OPC configuration is shown in Fig. 2(a). The WDM channels and a continuous wave (CW) pump from an ECL are separately amplified and band pass filtered before coupling them together at the input of a polarizationdiversity loop based on a polarization beam splitter (PBS) and a highly nonlinear fiber (HNLF). Four-wave mixing (FWM) in the HNLF performs the OPC operation. The pump wavelength and power at the HNLF input have been optimized to $1545.75 \mathrm{~nm}$ and $22 \mathrm{dBm}$ (per propagation direction), respectively, leading to a flat conversion efficiency (CE) of -17 dB over most of the C-band. Fig. 2(b) shows the CE measured by sweeping the wavelength of a single $\mathrm{CW}$ signal at the input of the OPC. Polarization dependence below $0.4 \mathrm{~dB}$ is achieved. The total input signal power has been optimized to $2 \mathrm{dBm}$, as a trade-off between optical signal-to-noise ratio (OSNR) degradation and nonlinear distortion [10]. The input and output spectra for the 5×WDM channels after 322-km transmission are shown in Fig. 2(b). The observed spectral tilt of both signal and idler bands is due to sub-optimum gain flattening. Negligible OSNR penalty $(<0.2 \mathrm{~dB})$ is introduced by the conversion as seen comparing input signal to output idler after amplification and optical bandpass filtering (OBPF). Finally, the use of a high-quality (10-kHz linewidth) pump laser further ensures a negligible penalty due to pump phase noise transfer [10].

\section{Transmission results}

The MI has been measured as a function of the total launched power at the input of each span and the results are shown in Fig. 3(a) and 3(b) for 644-km (4 loop turns) and 966-km (6 loop turns) transmission, respectively. The position of the OPC has been varied in steps of one loop turn $(161 \mathrm{~km})$ and the measured MI is benchmarked against straight transmission. In the nonlinear transmission regime ( $\left.\mathrm{P}_{\text {launch }}>-3 \mathrm{dBm}\right)$, the $\mathrm{MI}$ with $\mathrm{OPC}$ is always higher than for straight transmission (black dashed curves) regardless of the OPC position. However, the MI improvement is inversely proportional to the OPC offset from mid-link operation (red curves). At the optimum launched power, mid-link OPC provides an MI improvement of up to $0.17 \mathrm{bit} / \mathrm{symbol}$ and an SNR gain of $0.6 \mathrm{~dB}$. Such an improvement decreases when the position of the OPC is shifted away from the mid-point. Additionally, the optimum launched power for the mid-link $\mathrm{OPC}$ is increased by $2 \mathrm{~dB}$ compared to straight transmission. In the linear transmission regime $\left(\mathrm{P}_{\text {launch }}<-6 \mathrm{dBm}\right)$, the measured $\mathrm{MI}$ is unaffected by the presence of the OPC (compared to straight transmission), as long as the OPC is not positioned beyond the link mid-point. This further highlights that the conjugation does not induce significant penalty to the signal. When the OPC operation is shifted towards the end of the link, i.e. beyond the mid-point, the performance in the linear regime is degraded due to signal OSNR degradation prior to the conjugation stage. Due to the GFF configuration in our setup (Fig. 1), an ASE noise band 
co-propagates with the signals during the loop turns pre-OPC leading to additional OSNR degradation through gain competition in the in-line EDFA. As this effect is artificial and specific to our recirculating setup and would not impact an in-line transmission system, the measurements provide a lower bound on the achievable improvement for OPC positions beyond the link mid-point. For straight transmission, only the signal band is selected in the GFF.

The overall improvements in both received MI and SNR are summarized in Fig. 3(c) and (d), respectively. As expected for this link configuration [3], the maximum improvement is achieved for mid-link OPC operation, however, offsetting the OPC by $\pm 0.17 \cdot \mathrm{L}$ (one span for $966-\mathrm{km}$ transmission) still provides MI and SNR improvements. These results are in agreement with the numerical predictions of [6]. Additionally, a sub-optimum position of the OPC could be mitigated by combining OPC and low-complexity DBP as discussed in $[7,11]$.
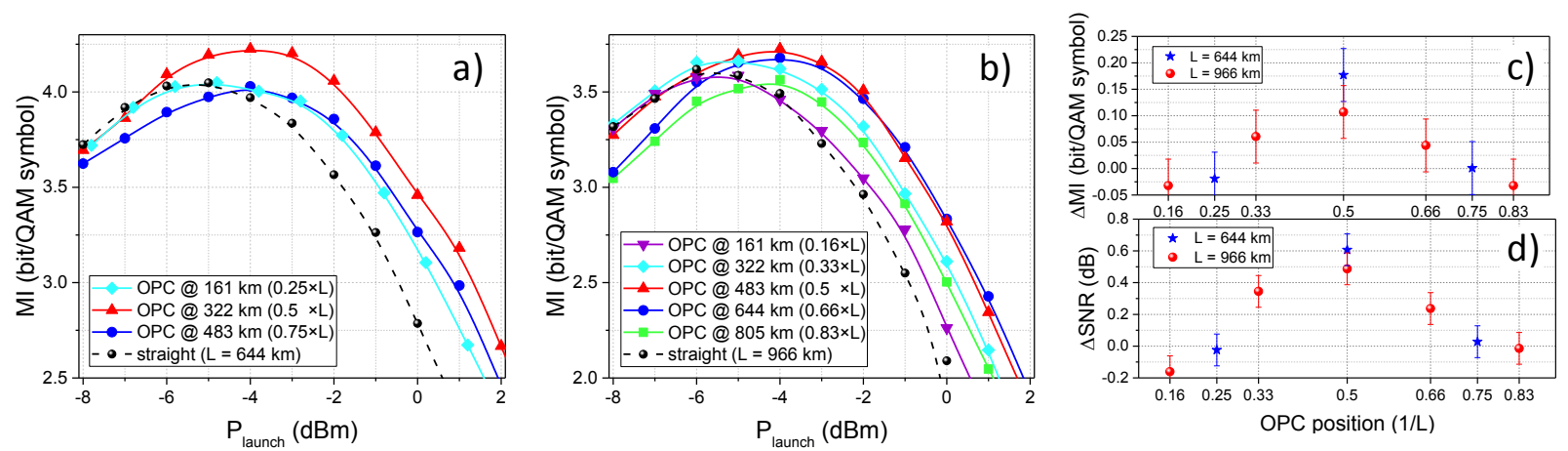

Fig. 3. MI as a function of the launched power for straight and OPC-based transmission for different OPC positions and a total transmission distance of $644 \mathrm{~km} \mathrm{(a)} \mathrm{and} 966 \mathrm{~km}$ (b). Improvements in MI (c) and SNR (d) as functions of the OPC position for both transmission distances. All measurements refer to the central channel.

\section{Conclusions}

We have investigated the improvement provided by OPC for dispersion-compensated transmission of a $5 \times$ WDM PDM 64-QAM signal for up to $966 \mathrm{~km}$ transmission. The impact of the OPC position on the nonlinearity compensation performance has been evaluated in terms of receiver MI and effective SNR demonstrating a gain in performance provided by the nonlinearity compensation, which decreases with the offset of the OPC from the link mid-point. Nevertheless, the increased nonlinearity tolerance in the nonlinear transmission regime is clearly visible for all of the evaluated OPC positions.

\section{Acknowledgements}

This work was supported by the DNRF CoE, SPOC (ref. DNRF123), and NANO-SPECs (DFF-4005-00558B).

\section{References}

[1] J. Cartledge, et al., "Signal processing techniques for reducing the impact of fiber nonlinearities on system performance," in Proc. OFC 2016, paper Th4F.5.

[2] T. Umeki, et al., "Simultaneous nonlinearity mitigation in $92 \times 180$-Gbit/s PDM-16QAM transmission over 3840 km using PPLN-based guard-band-less optical phase conjugation," Optics Express 24(15), 16945-16951 (2016).

[3]P. Minzoni, "Nonlinearity compensation in a fiber-optic link by optical phase conjugation," Fiber and Integrated Optics 28(3), 179-209 (2009).

[4] A.D. Ellis, et al., "4 Tb/s transmission reach enhancement using $10 \times 400 \mathrm{~Gb} / \mathrm{s}$ super-channels and polarization insensitive dual band optical phase conjugation,” Journal of Lightwave Technology 34(8), 1717-1723 (2016).

[5] Y. Sun, et al., "Optical nonlinearity mitigation of $6 \times 10 \mathrm{GBd}$ polarization-division multiplexing 16-QAM signals in a field-installed transmission link," in Proc. OFC 2017, paper Th3J.2.

[6] K. Solis-Trapala, et al., "Doubled transmission reach for DP-64QAM signal over field-deployed legacy fiber systems enabled by MSSI," in Proc. ECOC 2015, paper Mo.3.6.2.

[7] I. Kim, et al., "Impact of link symmetry on nonlinear noise mitigation using spectral inversion in superchannel transmission," in Proc. OECC/PS 2016, paper TuB3-2.

[8] D. Rafique, and A.D. Ellis, "Various nonlinearity mitigation techniques employing optical and electronic approaches," Photonics Technology Letters 23(23), 1838-1840 (2011).

[9] M.P. Yankov, et al., "Experimental analysis of pilot-based equalization for probabilistically shaped WDM systems with 256QAM/1024QAM," in Proc. OFC 2017, paper W.2.A.48.

[10] M.P. Yankov, et al., "Constellation shaping for WDM systems using 256QAM/1024QAM with probabilistic optimization," Journal of Lightwave Technology 32(22), 5146-5156 (2016).

[11] F. Da Ros, et al., "Impact of signal-conjugate wavelength shift on optical phase conjugation-based transmission of QAM signals," in Proc.

ECOC 2017, paper P1.SC4.66. 